Arq. Bras. Med. Vet. Zootec., v.67, n.3, p.827-836, 2015

\title{
Desempenho de vacas mestiças em função de suplementação energética e proteica em dietas à base de silagem de milho
}

\author{
[Performance of crossbred cows as a result of energetic and protein \\ supplementation in corn silage based diets] \\ L.I.M. Vargas ${ }^{1}$, R.P. Lana ${ }^{2,3^{*}}$, J.C.P. Modesto da Silva ${ }^{2}$, C.M. Veloso ${ }^{2}$, \\ L.N. Rennó ${ }^{2}$, D.M. Fonseca ${ }^{2}$ \\ ${ }^{1}$ Laboratório de Fisiologia y Nutrición Animal - CORPOICA - C.I. Tibaitatá - Bogotá, Colômbia \\ ${ }^{2}$ Universidade Federal de Viçosa - Viçosa, MG \\ ${ }^{3}$ Bolsista $1 \mathrm{~B}$ do $\mathrm{CNPq}$ \\ RESUMO
}

\begin{abstract}
Objetivou-se avaliar níveis de concentrados energéticos e proteicos sobre o desempenho de vacas leiteiras Holandês x Zebu, com peso corporal de $452 \pm 77 \mathrm{~kg}$, de terceira e quarta lactação, 80 dias pós-parto e produção de $12,8 \mathrm{~kg}$ de leite/dia. Nove vacas foram distribuídas em três quadrados latinos 3x3, em períodos experimentais de 10 dias, distribuídas segundo número de lactações, sendo os tratamentos níveis de farelo de soja (FS) em substituição ao fubá de milho (FM) $(0,8 ; 1,6$ e 2,4kg/vaca dia, completando para 3,2kg/vaca dia com FM), níveis de FS ou de FM $(0,8 ; 1,6$ e 3,2kg/vaca/dia) e silagem de milho como volumoso. Somente o consumo de proteína bruta se elevou com o aumento nos níveis de FS em dietas contendo FM+FS, ao passo que os consumos diários de matéria seca (MS) e das frações nutricionais aumentaram com a elevação do FS ou FM. Os coeficientes de digestibilidade da MS e dos nutrientes não diferiram em dietas contendo FM+FS. A digestibilidade da proteína bruta (PB) aumentou ao passar de 1,6 para 3,2kg/dia de FS. Houve diminuição da digestibilidade da MS, MO e CNF ao passar de 0,8 para 3,2kg/dia de FM e diminuição do NDT ao passar de 1,6 para 3,2kg/dia de FM. As exigências de NDT e PB só foram satisfeitas plenamente com $0,8+2,4 \mathrm{~kg}$ $(\mathrm{FM}+\mathrm{FS})$ e 3,2kg de FS. As dietas contendo FM não atenderam sequer às exigências de NDT. A produção de leite e a sua composição bem como o peso corporal e a eficiência alimentar relacionada ao CMS não foram influenciados pelos tratamentos. A eficiência alimentar em relação ao fornecimento de concentrado decresceu quando se adicionaram níveis crescentes de FS ou FM. Tendo como volumoso a silagem de milho, o fornecimento de fubá de milho ou farelo de soja, nas quantidades analisadas neste experimento, não promove aumento da produção de leite ou de seus constituintes, sendo que a eficiência do uso do concentrado diminui ao se elevar o nível de suplementação.
\end{abstract}

Palavras-chave: consumo, digestibilidade, farelo de soja, fubá de milho, leite

\begin{abstract}
The aim was to evaluate levels of energy and protein concentrates on performance of crossbred Holstein $x$ Zebu dairy cows, with body weight of $452 \pm 77 \mathrm{~kg}$, third and fourth lactation, 80 days post-partum and with a production of $12.8 \mathrm{~kg}$ of milk per day. Nine cows were distributed in three $3 \times 3$ Latin squares, with experimental periods of 10 days, distributed according to the number of lactations, with treatment levels of soybean meal (SBM) replacing corn meal (CM) $(0.8 ; 1.6$ and $2.4 \mathrm{~kg} / \mathrm{cow} /$ day completing $3.2 \mathrm{~kg} / \mathrm{cow} /$ day with CM); CM or SBM levels (0.8; 1.6 and $3.2 \mathrm{~kg} / \mathrm{cow} / \mathrm{day})$ and corn silage as forage. Only crude protein consumption rose with the increase in levels of $S B M$ in diets containing $C M+S B M$, while the daily consumption of dry mass (DM) and the nutrient fractions increased with the elevation of CM or SBM. The coefficients of digestibility of DM and nutrients did not differ in diets containing $C M+S B M$. The crude protein $(C P)$ digestibility increased when changing from 1.6 to $3.2 \mathrm{~kg} /$ day of SBM. There was reduction of digestibility of DM, OM, and NFC when passing from 0.8 to $3.2 \mathrm{~kg} /$ day of CM and decrease of TDN when changing from
\end{abstract}

Recebido em 11 de abril de 2013

Aceito em 12 de março de 2015

*Autor para correspondência (corresponding author)

E-mail: rlana@ufv.br 
1.6 to $3.2 \mathrm{~kg} /$ day of $C M$. The requirements for TDN and CP were only fully satisfied fully in diets containing $0.8+2.4 \mathrm{~kg}(C M+S B M)$ and $3.2 \mathrm{~kg}$ of SBM. Diets containing CM did not attend even the demands of TDN. Milk production and composition, as well as the body weight and food efficiency related to the DMI were not influenced by the treatments. Feed efficiency in relation to the supply of concentrate decreased when increasing levels of CM or SBM were added. Having corn silage as forage, the supply of corn meal or soybean meal in quantities analyzed in this experiment does not promote increase in production of milk or their constituents, and the efficiency of the use of concentrate decreases when raising the level of supplementation.

Keywords: corn meal, digestibility, intake, milk, soybean meal

\section{INTRODUÇÃO}

Em sistemas de produção de leite caracterizados pela redução da margem de lucro em consequência do aumento do custo de alimentação, deve-se considerar o uso de fontes alimentares de suplementação. Na composição do custo de alimentação, não só os alimentos concentrados, mas também os volumosos, têm participação importante, pois representam de 40 a $80 \%$ da matéria seca (MS) da dieta das várias categorias que compõem o rebanho leiteiro. Portanto, os produtores deverão dispor de alternativas viáveis com vistas a minimizar custos de produção e reduzir a adoção de tecnologias que demandem consideráveis custos em recursos técnicos e financeiros.

A adequação do manejo produtivo e reprodutivo de vacas leiteiras pressupõe a compreensão das variações na ingestão de MS, peso corporal e produção de leite. Durante a fase inicial de lactação (zero a 100 dias pós-parto), a vaca leiteira passa por transformações anatômicas, fisiológicas e endócrinas, que modificam seu metabolismo e contribuem para uma reduzida capacidade de consumo de MS (Janssen, 1994; Grant e Albright, 1995). Após 10 a 12 semanas pós-parto, quando ocorre o pico de consumo de MS, a produção leiteira decresce gradativamente (National..., 2001).

O maior uso de alimentos concentrados tem sido adotado a fim de otimizar a produção leiteira ao fornecer nutrientes complementares deficientes na forragem. Entretanto, o uso de concentrados deve ser avaliado em termos de sua eficiência (quilo de leite por quilo de suplemento, comparado ao tratamento controle), devido ao fato de o concentrado ser de alto custo e a alimentação corresponder a até $70 \%$ do custo de produção bovina (Lana, 2009; Oliveira et al., 2011).
A proteína constitui o segundo nutriente de maior importância na alimentação dos ruminantes. A proteína dietética ingerida é degradada pelos microrganismos do rúmen em uma proporção que dependerá das características da fonte proteica e da ração. A exigência de proteína por vacas leiteiras é atendida através da absorção de aminoácidos pelo intestino delgado, provenientes da proteína microbiana verdadeira (proteína degradada no rúmen, PDR) e da proteína dietética não degradada no rúmen (PNDR), contribuindo para o suprimento de proteína metabolizável (National..., 2001).

Assim, foi desenvolvido este experimento com vacas mestiças Holandês-Zebu, com o objetivo de avaliar os efeitos de níveis e fontes de suplementos concentrados sobre o consumo e digestibilidade dos nutrientes, produção e composição de leite.

\section{MATERIAL E MÉTODOS}

A pesquisa foi conduzida na Fazenda Cachoeirinha, pertencente à Universidade Federal de Viçosa (UFV), em Viçosa-MG, durante os meses de setembro a novembro de 2009, e as análises laboratoriais, para determinação de matéria seca e composição química dos alimentos, das fezes e das sobras, foram executadas no Laboratório de Nutrição Animal do Departamento de Zootecnia da UFV.

A cidade de Viçosa se localizada na região da Zona da Mata, Estado de Minas Gerais, a 649m de altitude, geograficamente definida pelas coordenadas $20^{\circ} 45^{\prime} 20^{\prime \prime}$ de latitude sul e $42^{\circ} 52^{\prime}$ $40 "$ de longitude oeste. O clima é de tipo Cwa, segundo a classificação de Köppen, tendo duas estações definidas: seca, de abril a setembro, e águas, de outubro a março. $\mathrm{O}$ verão é quente e úmido e o inverno, frio e seco. 
Foram utilizadas nove vacas mestiças (Holandês $\mathrm{x}$ Zebu), com peso corporal médio inicial de $452 \pm 77 \mathrm{~kg}$, entre terceira e quarta lactação, 80 dias pós-parto e com produção de leite média de $12,8 \mathrm{~kg} /$ dia. Os animais foram distribuídos em três quadrados latinos com três animais em cada um para testar níveis de farelo de soja em substituição ao fubá de milho; níveis de farelo de soja e níveis de fubá de milho em dietas à base de silagem de milho (Tab. 1), constituindo nove tratamentos. A composição bromatológica das dietas experimentais encontra-se na Tab. 2.

Tabela 1. Composição em ingredientes das dietas experimentais, em porcentagem da matéria seca (\%MS)

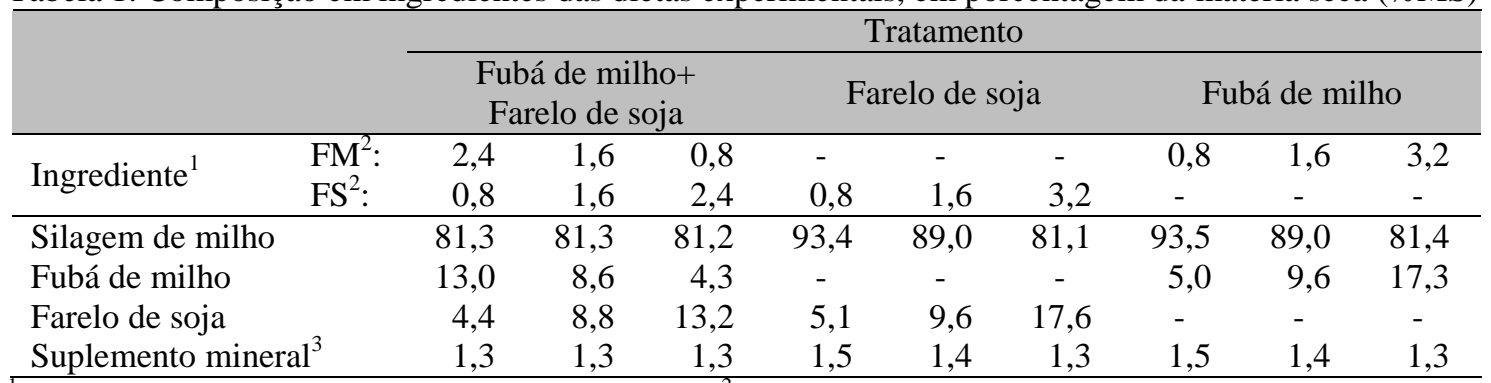

${ }^{1}$ Porcentagem da matéria seca das dietas experimentais; ${ }^{2} \mathrm{~kg}$ de matéria natural de fubá de milho (FM) e/ou farelo de soja (FS)/vaca dia. ${ }^{3}$ Suplemento mineral comercial: cálcio (15,6\%); fósforo (5,1\%); enxofre (2,0\%); magnésio $(3,3 \%)$; sódio $(9,3 \%)$; potássio $(2,82 \%)$; cobalto $(0,003 \%)$; cobre $(0,040 \%)$; cromo $(0,001 \%)$; ferro $(0,2 \%)$; iodo $(0,004 \%)$; manganês $(0,135 \%)$; selênio $(0,002 \%)$; flúor $(0,051 \%)$; zinco $(0,170 \%)$; vitamina A $(135.000,00$ U.I. $)$; vitamina D3 (68.000,00 U.I.); vitamina E (450,00 U.I.). Solubilidade do fósforo de $95 \%$.

Tabela 2. Composição químico-bromatológica da silagem de milho e das dietas experimentais ${ }^{1}$

\begin{tabular}{|c|c|c|c|c|c|c|c|c|c|c|}
\hline \multirow{3}{*}{ Item } & \multirow{3}{*}{$\begin{array}{c}\text { Silagem } \\
\text { de } \\
\text { milho }\end{array}$} & \multicolumn{9}{|c|}{ Dieta experimental $^{2}$} \\
\hline & & FM: 2,4 & 1,6 & 0,8 & - & - & - & 0,8 & 1,6 & 3,2 \\
\hline & & FS: 0,8 & 1,6 & 2,4 & 0,8 & 1,6 & 3,2 & - & - & - \\
\hline Matéria seca & 31,22 & 41,49 & 41,54 & 41,61 & 35,00 & 37,41 & 41,68 & 34,93 & 37,28 & 41,43 \\
\hline Matéria orgânica $^{1}$ & 94,30 & 93,78 & 93,55 & 93,34 & 92,96 & 92,93 & 93,12 & 93,22 & 93,42 & 94,01 \\
\hline Matéria mineral $^{1}$ & 5,70 & 6,27 & 6,49 & 6,71 & 7,09 & 7,03 & 6,94 & 6,83 & 6,54 & 6,05 \\
\hline Proteína bruta $^{1}$ & 6,32 & 8,80 & 10,79 & 12,79 & 8,69 & 10,91 & 14,78 & 6,39 & 6,53 & 6,80 \\
\hline PIDN $(\% \mathrm{MS})^{1,}$ & 2,32 & 2,16 & 2,28 & 2,40 & 2,35 & 2,41 & 2,52 & 2,22 & 2,15 & 2,04 \\
\hline PIDA $(\% \mathrm{MS})^{1}$ & 0,52 & 0,61 & 0,71 & 0,81 & 0,63 & 0,73 & 0,91 & 0,51 & 0,51 & 0,51 \\
\hline Extrato etéreo $^{1}$ & 1,54 & 1,61 & 1,56 & 1,51 & 1,50 & 1,48 & 1,45 & 1,56 & 1,59 & 1,66 \\
\hline $\mathrm{FDN}^{1}$ & 49,50 & 42,70 & 43,07 & 43,44 & 47,33 & 46,00 & 43,81 & 46,91 & 45,19 & 42,34 \\
\hline FDNcp $^{1}$ & 29,46 & 39,35 & 39,60 & 39,86 & 43,70 & 42,35 & 40,12 & 43,41 & 41,79 & 39,10 \\
\hline $\mathrm{FDA}^{1}$ & 6,32 & 24,60 & 24,93 & 25,25 & 28,03 & 27,10 & 25,58 & 27,65 & 26,39 & 24,28 \\
\hline Lignina $^{1}$ & 3,99 & 3,49 & 3,44 & 3,40 & 3,76 & 3,61 & 3,35 & 3,82 & 3,71 & 3,54 \\
\hline Carboidratos totais $^{1}$ & 86,44 & 83,32 & 81,16 & 78,99 & 82,72 & 80,58 & 76,83 & 85,22 & 85,34 & 85,49 \\
\hline Carboidratos não fibrosos 1 & 56,98 & 43,97 & 41,56 & 39,13 & 39,02 & 38,23 & 36,70 & 41,81 & 43,55 & 46,39 \\
\hline $\mathrm{FDNi}^{1}$ & 18,64 & 15,28 & 15,27 & 15,26 & 17,47 & 16,64 & 15,25 & 17,48 & 16,66 & 15,29 \\
\hline
\end{tabular}

${ }^{1}$ Valores em porcentagem da matéria seca; PIDN = proteína insolúvel em detergente neutro; PIDA = proteína insolúvel em detergente ácido; FDN = fibra em detergente neutro FDNcp = fibra em detergente neutro corrigida para cinza e proteína; FDA = fibra em detergente ácido; $\mathrm{FDNi}=$ fibra em detergente neutro indigestível; ${ }^{2} \mathrm{FM}=$ fubá de milho (kg/vaca dia); FS = farelo de soja (kg/vaca/dia).

Cada quadrado latino foi avaliado por três períodos experimentais, com duração de 10 dias cada período, sendo os sete primeiros dias destinados à adaptação às dietas e os demais dias para avaliação de consumo, digestibilidade dos componentes das dietas, produção de leite e variação de peso corporal.
As vacas foram alojadas em baias individuais, com cerca de arame farpado e piso de terra batida, com área coberta de $24 \mathrm{~m}^{2}$, dotadas de cocho coberto para fornecimento de alimentos, bebedouro para fornecimento de água e saleiro.

Os animais receberam silagem de milho, diariamente, pela manhã, permitindo-se $10 \%$ de sobras, além de sal mineral e água à vontade. Os 
concentrados foram fornecidos duas vezes ao dia, durante as ordenhas da manhã e da tarde.

Para avaliar o consumo voluntário, realizaram-se pesagens individuais, diárias, dos concentrados e da silagem fornecidos, mantendo-se as sobras de alimento na ordem de $10 \%$, com base na matéria natural.

Para avaliação e quantificação de consumo voluntário, foram considerados os alimentos fornecidos entre o sexto e nono dia de cada período experimental, sendo as sobras computadas entre o sétimo e décimo dia. Amostras dos alimentos fornecidos, e sobras no final de cada período experimental, foram compostas, de forma representativa, por animal e por período, e armazenadas em sacos plásticos e congeladas $\left(-20^{\circ} \mathrm{C}\right)$, para posteriormente serem processadas.

Para estimação dos coeficientes de digestibilidade, foram realizadas coletas de fezes diretamente do reto dos animais, em três dias consecutivos (sétimo ao nono dia de cada período experimental), segundo a distribuição: $7^{\mathrm{o}}$ dia - 6 h e $14 \mathrm{~h}, 8^{\circ}$ dia $-8 \mathrm{~h}$ e $16 \mathrm{~h}$ e $9^{\circ}$ dia $-10 \mathrm{~h}$ e 18h. As amostras foram acondicionadas em sacos plásticos e congeladas $\left(-20^{\circ} \mathrm{C}\right)$. No décimo dia de cada período experimental, foram registrados a produção de leite e o peso corporal. As vacas foram ordenhadas, mecanicamente, duas vezes por dia, às 6:00h e 14:00h, com a presença dos bezerros durante as ordenhas. Para análises laboratoriais, as amostras compostas dos alimentos fornecidos, sobras de volumoso e fezes, por animal e por período experimental, foram descongeladas e pré-secas em estufa de ventilação forçada $\left(60^{\circ} \mathrm{C} / 72-96 \mathrm{~h}\right)$. Foram homogeneizadas e processadas em moinho tipo Willey, com peneira de malha de $1 \mathrm{~mm}$. Posteriormente, elaboraram-se amostras compostas por animal e período experimental, com base no peso da amostra seca ao ar, as quais foram acondicionadas em potes plásticos.

As análises da composição em matéria seca (MS), dos teores de material mineral (MM), extrato etéreo (EE), proteína bruta $(\mathrm{PB})$ e lignina $\left(\mathrm{H}_{2} \mathrm{SO}_{4} 72 \% \mathrm{p} / \mathrm{p}\right)$ foram realizadas segundo procedimentos descritos por Silva e Queiroz (2002).

Os teores de fibra em detergente neutro (FDN) foram estimados segundo recomendações de
Mertens (2002), utilizando-se alfa-amilase termoestável. As correções no tocante aos teores de cinzas e proteína contidos na FDN e na fibra em detergente ácido (FDA) foram conduzidas conforme recomendações de Mertens (2002) e Licitra et al. (1996), respectivamente.

As avaliações dos teores de FDN e FDA foram feitas em analisador de fibras (Ankom ${ }^{\circledR}$ ). A metodologia do aparelho foi adaptada para análise de FDN e FDA em sacos de tecido-nãotecido (TNT, $100 \mathrm{~g} / \mathrm{m}^{2}$, dimensão 4x5). Amostras de alimentos, sobras e fezes foram moídas em tamanho de $1 \mathrm{~mm}$. A relação detergente neutro:amostra foi mantida em $100 \mathrm{~mL} / \mathrm{g}$ de $\mathrm{MS}$, com tempo efetivo de extração de uma hora.

As amostras foram submetidas à lavagem com detergente neutro por uma hora, em temperatura de $100^{\circ} \mathrm{C}$. Após a extração, foram realizadas lavagens sequenciais com água quente e acetona. Após esse procedimento, os sacos foram secos em estufa com ventilação forçada $\left(60^{\circ} \mathrm{C} / 72\right.$ horas) e, sequencialmente, em estufa não ventilada $\left(105^{\circ} \mathrm{C} / 45\right.$ minutos), acondicionados em dessecador e pesados. Para o manejo do dessecador, os sacos foram colocados em grupos não superiores a 20 unidades, para que o tempo de pesagem não se tornasse demasiadamente prolongado e houvesse alteração de peso devido à higroscopicidade da fibra. Após a determinação da FDN, foi realizada a determinação da FDA, sequencialmente, utilizando-se a mesma metodologia, substituindo-se o detergente neutro pelo detergente ácido e sem o uso de alfaamilase.

O teor de carboidratos totais (CT) foi calculado segundo Sniffen et al. (1992):

$\mathrm{CT}=100-(\% \mathrm{~PB}+\% \mathrm{EE}+\% \mathrm{MM})$.

O teor de carboidratos não fibrosos (CNF) foi calculado como proposto por Detmann e Valadares Filho (2010), sendo: CNF = $100-$ (MM - EE - FDNcp - PB).

Os valores observados de nutrientes digestíveis totais (NDT) das dietas foram obtidos conforme Weiss et al. (1992), adotado pelo NRC (National..., 2001): NDT $(\%)=$ PBd + FDNd + $\mathrm{CNFd}+2,25 \mathrm{x}$ EEd, em que PBd, FDNd, CNFd e EEd representam o total de nutrientes digestíveis e NDT encontra-se na base da matéria seca das dietas. 
As estimativas de excreção fecal foram obtidas utilizando-se a fibra em detergente neutro indigestível (FDNi) como indicador interno. As amostras de silagem e fezes, secas e moídas em peneira de malha de $2 \mathrm{~mm}$, foram acondicionadas em sacos de TNT $\left(100 \mathrm{~g} / \mathrm{m}^{2}\right.$, dimensão $\left.4 \times 5 \mathrm{~cm}\right)$ em triplicata, obedecendo à relação de $27 \mathrm{mg}$ de MS por centímetro quadrado de superfície. Os sacos foram incubados via fístula no rúmen de uma novilha mestiça recebendo dieta mista, por 264 horas (Casali et al., 2008). Após o período de incubação, os sacos foram lavados em água corrente até a mesma apresentar-se totalmente límpida. Posteriormente, os sacos com amostra foram submetidos à extração com detergente neutro (Mertens, 2002), durante uma hora, para serem submetidos à análise de FDNi. Os valores de excreção fecal foram obtidos por intermédio da relação entre o consumo e a concentração fecal de FDNi.

As amostras de leite foram obtidas das ordenhas nos horários da manhã (2/3) e da tarde (1/3), sendo compostas por animal e por período, acondicionadas em frascos contendo Bronopol ${ }^{\circledR}$, mantidas entre 2 e $6^{\circ} \mathrm{C}$, e enviadas para o Laboratório de Qualidade do Leite do Centro Nacional de Pesquisas de Gado de Leite, CNPGL-EMBRAPA, em Juiz de Fora-MG, para análise dos teores de proteína, gordura, lactose, extrato seco total e contagem de células somáticas, segundo metodologia descrita pelo International Dairy Federation (International..., 1996). A produção de leite corrigida para 3,5\% de gordura (PLG) foi obtida pela equação citada por Sklan et al. (1992), em que PLG $=(0,432+$ $0,1625 \times \mathrm{G}) \times \mathrm{Kg}$ de leite, em que $\mathrm{G}=\%$ de gordura no leite.

A eficiência alimentar foi calculada dividindo-se a produção média de leite/vaca pela ingestão média de MS em cada período experimental (Valadares Filho et al., 2000).

Os resultados foram submetidos à análise estatística, utilizando o programa PROC GLM (SAS, 9.0), sendo o delineamento em quadrado latino (QL), incluindo efeito de tratamento, QL, animal dentro de QL e período dentro de QL.

Os resultados foram submetidos à análise de variância e teste de média (Tukey), adotando-se o nível de significância de $10 \%$, para avaliar o efeito dos níveis de suplementação energética e proteica sobre as variáveis: consumo, digestibilidade, produção e composição de leite e eficiência alimentar.

\section{RESULTADOS}

O consumo de matéria seca e das frações nutricionais em dietas à base de fubá de milho+farelo de soja não foi influenciado pelos tratamentos $(\mathrm{P}>0,10)$, exceto o consumo de proteína bruta $(\mathrm{kg} / \mathrm{dia}$ e $\mathrm{g} / \mathrm{kg}$ de peso corporal), o qual se elevou com o aumento nos níveis de farelo de soja (Tab. 3).

Os consumos de matéria seca e das frações nutricionais em $\mathrm{kg} / \mathrm{dia}$ e $\mathrm{g} / \mathrm{kg}$ de peso corporal aumentaram $(\mathrm{P}<0,10)$ com o incremento do nível de farelo de soja, exceto o consumo de fibra em detergente neutro (FDNcp) e carboidratos não fibrosos (CNFcp), corrigidos para cinzas e proteína expressos em $\mathrm{g} / \mathrm{kg}$ de peso corporal, que não foram afetados $(\mathrm{P}>0,10)$ (Tab. 3). Os testes de média mostraram que os consumos diários de volumoso, extrato etéreo, FDNcp e CNFcp somente aumentaram quando o farelo de soja passou de 0,8 para $1,6 \mathrm{~kg} / \mathrm{dia}$, e o consumo de nutrientes digestíveis totais (NDT) aumentou, apenas, quando se adicionou $3,2 \mathrm{~kg} / \mathrm{dia}$ de farelo de soja (Tab. 3).

Em dietas à base de fubá de milho, os consumos diários de matéria seca total e de volumoso, matéria orgânica, proteína bruta, extrato etéreo, FDNcp e CNFcp se elevaram $(\mathrm{P}<0,10)$ à medida que se aumentou o nível do mesmo. Os testes de média mostraram que os consumos diários de volumoso e NDT somente aumentaram quando a adição de farelo de soja passou de 0,8 para 1,6kg/dia (Tab. 3).

Os coeficientes de digestibilidade da MS e dos nutrientes não diferiram $(\mathrm{P}>0,10)$ quando se adicionaram diferentes níveis de farelo de soja misturado ao fubá de milho (Tab. 4). Nas dietas à base de farelo de soja, o efeito ficou restrito à digestibilidade da $\mathrm{PB}$, que aumentou $(\mathrm{P}<0,10)$ quando a adição de farelo de soja passou de 1,6 para 3,2kg/dia (Tab. 4).

Houve diminuição da digestibilidade da MS, MO e CNF quando se aumentou o fubá de milho de 0,8 para $3,2 \mathrm{~kg} /$ dia para as dietas à base de fubá de milho $(\mathrm{P}<0,10)$. A digestibilidade da $\mathrm{PB}, \mathrm{EE}$ e FDNcp não se alterou com os tratamentos. O 
valor de NDT diminuiu apenas quando se forneceu 3,2kg/dia de fubá de milho (Tab. 4).

Ao comparar os valores estimados e observados de consumo de MS, NDT e PB (Tab. 4), verificase que as exigências de NDT e PB só foram satisfeitas plenamente nas dietas contendo $0,8+2,4 \mathrm{~kg}$ (fubá de milho + farelo de soja) e 3,2kg de farelo de soja. As dietas contendo fubá de milho não atenderam sequer às exigências de NDT, devido aos menores valores de NDT e consumo de MS observados (Tab. 4 e 5).

A produção de leite e a sua composição não foram influenciadas pelos tratamentos $(\mathrm{P}>0,10)$ (Tab. 6).

Tabela 3. Consumo de matéria seca e frações nutricionais em vacas mestiças alimentadas com diferentes quantidades de fubá de milho ( $\mathrm{kg} /$ dia) e farelo de soja $(\mathrm{kg} / \mathrm{dia})$

\begin{tabular}{|c|c|c|c|c|c|c|c|c|c|c|c|c|c|c|c|}
\hline \multirow{2}{*}{$\begin{array}{l}\text { Item } \\
\text { FM: }\end{array}$} & \multicolumn{5}{|c|}{$\begin{array}{l}\text { Fubá de milho+ } \\
\text { Farelo de soja }\end{array}$} & \multicolumn{5}{|c|}{ Farelo de soja $^{1}$} & \multicolumn{5}{|c|}{ Fubá de milho $^{1}$} \\
\hline & 2,4 & 1,6 & 0,8 & Valor & $\mathrm{CV}$ & - & - & - & Valor & $\mathrm{CV}$ & 0,8 & 1,6 & 3,2 & Valor & V \\
\hline FS: & 0,8 & 1,6 & 2,4 & $P$ & $(\%)$ & 0,8 & 1,6 & 3,2 & $\mathrm{P}$ & $(\%)$ & - & $\pi$ & - & $\mathrm{P}$ & $(\%)$ \\
\hline MS & 14,4 & 14,4 & 14,7 & 0,688 & 2,7 & $12,4 \mathrm{c}$ & $13,8 b$ & $4,6 \mathrm{a}$ & 0,011 & 1,5 & $11,1 \mathrm{c}$ & $12,9 b$ & $14,2 \mathrm{a}$ & 0,015 & 2,6 \\
\hline Ms & 11,5 & 11,5 & 11,8 & 0,712 & 3,4 & $11,5 b$ & $12,2 \mathrm{a}$ & $11,7 \mathrm{ab}$ & 0,091 & 1,7 & $10,2 b$ & $11,4 a$ & $11,4 a$ & 0,077 & 3,1 \\
\hline MS & 33,9 & 34,9 & 33,7 & 0,693 & 4,7 & $25,2 b$ & $28,7 \mathrm{ab}$ & $32,1 \mathrm{a}$ & 0,095 & 6,7 & 28,0 & 24,7 & 30,1 & 0,379 & 13,2 \\
\hline ,75) & 154 & 157 & 154 & 0,784 & 3,9 & $118 \mathrm{~b}$ & $134 \mathrm{ab}$ & 148 & 0,072 & 5,3 & 124 & 118 & 140 & 15 & 10,4 \\
\hline 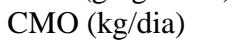 & 13,5 & 13,4 & 13,7 & 0,615 & 2,6 & & & & & & $10,3 \mathrm{c}$ & $12,0 \mathrm{~b}$ & $13,3 \mathrm{a}$ & & 0 \\
\hline $\mathrm{DI}$ & & $1,59 b$ & 100 & $<0$ & 1,2 & & & & & & 0 & 0,8 & & & \\
\hline $\mathrm{EI}$ & 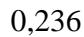 & 0,22 & 0 & 0,318 & 20 & & & & & & 0 , & 0,2 &, 242 & 09 & 2,6 \\
\hline $\mathrm{FI}$ & 5,62 & 5,61 & 5,76 & 0,560 & 2,9 & $5,35 \mathrm{~b}$ & $5,82 \mathrm{a}$ & $5,77 \mathrm{a}$ & 0,047 & 1,7 & 4,46 & 5,32 & $5,47 a$ & 0,077 & 5,3 \\
\hline $\mathrm{CN}$ & 6 & 6,05 & 5,82 & 0,131 & 3 , & $4,91 \mathrm{~b}$ & 5,3 & 5,4 & 0 , & 1 & $4,92 \mathrm{c}$ & $5,70 \mathrm{~b}$ & $6,71 \mathrm{a}$ & $<0,001$ & 0,8 \\
\hline & 9 & 7,85 & 8,53 & 0,616 & 18 & & & & & & $5,57 \mathrm{~b}$ & $6,29 a$ & $6,37 \mathrm{a}$ & 0,062 & 3,2 \\
\hline & 3 & 32 & 31 & 0,759 & 4 & & & & & & & & 283 & 60 & 13 \\
\hline & & 3,8 & & & 3 & & & & & & & & 0 & & \\
\hline & & $6=$ & & 0,277 & 4, & & $0,432 \mathrm{ab}$ & 0,4 & & & 0,449 & 0,405 & 0,512 & 71 & 12 \\
\hline ח & 13 , & 13 & 3 , & 0,782 & 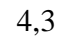 & & & 12 & 0,201 & 6 , & 11,2 & 10,1 & & 0,676 & 16 \\
\hline $\mathrm{CN}$ & 15,0 & 14,7 & 13,3 & 0,214 & ד, & 10,0 & 11, & 12,0 & 0,172 & (5) & 12,5 & 10,9 & 14,1 & 0,187 & 10,7 \\
\hline NDT (g/kgPC) & 21,7 & 19,1 & 19,6 & 0,758 & 21,4 & 12,7 & 13,5 & 18,3 & 0,098 & 11,5 & 14,1 & 12,0 & 13,3 & 0,384 & 11,2 \\
\hline
\end{tabular}

$\mathrm{FM}$ = fubá de milho; FS = farelo de soja; $\mathrm{MS}$ = matéria seca; $\mathrm{MO}=$ matéria orgânica; $\mathrm{PB}$ = proteína bruta; $\mathrm{EE}=$ extrato etéreo; FDNcp = fibra em detergente neutro corrigido para cinzas e proteína; $\mathrm{CNF}=$ carboidratos não fibrosos corrigidos para cinzas e proteína; $\mathrm{CV}=$ coeficiente de variação. ${ }^{1}$ Médias seguidas por letras diferentes, dentro de cada tratamento, diferem pelo teste Tukey $(\mathrm{P}<0,10)$.

Tabela 4. Digestibilidade da matéria seca e frações nutricionais e teor de nutrientes digestíveis totais em vacas mestiças alimentadas com diferentes quantidades de fubá de milho (kg/dia) e farelo de soja ( $\mathrm{kg} / \mathrm{dia})$

\begin{tabular}{|c|c|c|c|c|c|c|c|c|c|c|c|c|c|c|c|}
\hline \multirow{3}{*}{$\begin{array}{l}\text { Item } \\
\text { FM: } \\
\text { FS: }\end{array}$} & \multicolumn{5}{|c|}{ Fubá de milho+Farelo de soja } & \multicolumn{5}{|c|}{ Farelo de soja ${ }^{1}$} & \multicolumn{5}{|c|}{ Fubá de milho ${ }^{1}$} \\
\hline & 2,4 & 1,6 & 0,8 & Valor & $\mathrm{CV}$ & - & - & & Valor & $\mathrm{CV}$ & 0,8 & 1,6 & 3,2 & Valor & $\mathrm{CV}$ \\
\hline & 0 & 1,6 & & $P$ & $(\%)$ & 0,8 & 1,6 & 3,2 & $\mathrm{P}$ & $(\%)$ & & & & $D$ & $(\%)$ \\
\hline & 5,6 & & & & 17 & & & 8 & & 5,8 & & 56 & $47,3 b$ & 41 & 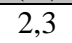 \\
\hline M & & 6 & & & 3 & & 49,2 & 59,0 & 27 & 0 & $52,8 \mathrm{a}$ & & $3 b$ & 69 & 1 \\
\hline $1+$ & 7 & 58,3 & & & 12,3 & $5 b$ & $48,4 \mathrm{~b}$ & $71,5 a$ & 0,007 & 3,9 & 26,7 & 25,8 & 23,9 & 0,920 & 33,8 \\
\hline EE & 1,2 & 61,2 & 68 & & 12,9 & & 39,7 & 63,6 & 0,257 & 23,3 & 50,2 & 56,4 & 42,8 & 0,593 & 28,4 \\
\hline FDl & 54,1 & 43,0 & 52,6 & 0,472 & 19,7 & 44,1 & 45,9 & 48,9 & 0,603 & 11,3 & 46,0 & 44,2 & 40,9 & 0,654 & 13,9 \\
\hline $\mathrm{CNI}$ & 79,2 & 68,6 & 64,1 & 0,608 & 23,7 & 64,0 & 53,4 & 63,5 & 0,276 & 105 & $62,0 \mathrm{a}$ & $58,8 \mathrm{ab}$ & $52,6 \mathrm{~b}$ & 0,091 & 4,5 \\
\hline IDT & 64,1 & 54,5 & 57,8 &, 629 & 18,8 & 50,5 & 47,5 & 56,5 & 0,142 & 6,5 & $50,2 \mathrm{a}$ & $48,5 \mathrm{a}$ & $44,3 b$ & 0,041 &, 3 \\
\hline
\end{tabular}

FM = fubá de milho; FS = farelo de soja; MS = matéria seca; $\mathrm{MO}=$ matéria orgânica; $\mathrm{PB}$ = proteína bruta; $\mathrm{EE}=$ extrato etéreo; $\mathrm{FDNcp}$ = fibra em detergente neutro corrigido para cinzas e proteína; $\mathrm{CNF}=$ carboidratos não fibrosos corrigidos para cinzas e proteína; $\mathrm{CV}=$ coeficiente de variação. ${ }^{1}$ Médias seguidas por letras diferentes, dentro de cada tratamento, diferem pelo teste Tukey $(\mathrm{P}<0,10)$. 
Tabela 5. Valores estimados e observados de consumo de matéria seca (MS), nutrientes digestíveis totais (NDT) e proteína bruta (PB) em vacas mestiças alimentadas com diferentes quantidades de fubá de milho - FM (kg/dia) e farelo de soja - FS (kg/dia)

\begin{tabular}{|c|c|c|c|c|c|c|c|c|c|c|}
\hline \multirow{3}{*}{ Item } & \multirow{3}{*}{ Exigência $^{1}$} & \multicolumn{3}{|c|}{$\begin{array}{c}\text { Fubá de milho+Farelo de } \\
\text { soja }\end{array}$} & \multicolumn{3}{|c|}{ Farelo de soja } & \multicolumn{3}{|c|}{ Fubá de milho } \\
\hline & & FM: 2,4 & 1,6 & 0,8 & - & - & - & 0,8 & 1,6 & 3,2 \\
\hline & & FS: 0,8 & 1,6 & 2,4 & 0,8 & 1,6 & 3,2 & - & - & - \\
\hline MS & 13,7 & 14,20 & 14,40 & 14,70 & 12,40 & 13,80 & 14,60 & 11,10 & 12,90 & 14,20 \\
\hline Diferença & & $+0,50$ & $+0,70$ & $+1,00$ & $-1,30$ & $+0,10$ & $+0,90$ & $-2,60$ & $-0,80$ & $+0,50$ \\
\hline NDT & 8,43 & 9,25 & 7,85 & 8,53 & 6,26 & 6,49 & 8,29 & 5,75 & 6,29 & 6,37 \\
\hline Diferença & & $+0,82$ & $-0,58$ & $+0,10$ & $-2,17$ & $-1,94$ & $-0,14$ & $-2,68$ & $-2,14$ & $-2,06$ \\
\hline PB & 1,82 & 1,29 & 1,59 & 1,90 & 1,11 & 1,51 & 2,21 & 0,74 & 0,86 & 0,98 \\
\hline Diferença & & $-0,53$ & $-0,23$ & $+0,08$ & $-0,71$ & $-0,31$ & $+0,39$ & $-1,08$ & $-0,96$ & $-0,84$ \\
\hline
\end{tabular}

${ }^{1}$ Sistema Viçosa de Formulação de Rações (Lana 2007), com base em dados do NRC (National..., 2001) para vacas lactantes com $452 \mathrm{~kg}$ de peso corporal e produção de leite de $12,8 \mathrm{~kg} / \mathrm{dia}$ com 3,5\% de gordura.

Tabela 6. Produção e composição do leite em vacas mestiças alimentadas com diferentes quantidades de fubá de milho e farelo de soja (kg/dia)

\begin{tabular}{|c|c|c|c|c|c|c|c|c|c|c|c|c|c|c|c|}
\hline \multirow{3}{*}{$\begin{array}{l}\text { Item } \\
\text { FM: } \\
\text { FS: }\end{array}$} & \multicolumn{5}{|c|}{ Fubá de milho+Farelo de soja ${ }^{1}$} & \multicolumn{5}{|c|}{ Farelo de soja ${ }^{1}$} & \multicolumn{5}{|c|}{ Fubá de milho ${ }^{1}$} \\
\hline & 2,4 & 1,6 & 0,8 & Valor & $\mathrm{CV}$ & - & - & 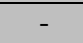 & Valor & $\mathrm{CV}$ & 0,8 & 1,6 & 3,2 & Valor & $\mathrm{CV}$ \\
\hline & 0,8 & 1,6 & 2,4 & $\mathrm{P}$ & $(\%)$ & 0,8 & 1,6 & 3,2 & $\mathrm{P}$ & $(\%)$ & - & - & - & $\mathrm{P}$ & $\%)$ \\
\hline $\begin{array}{l}\text { Produção de } \\
\text { leite (kg/dia) }\end{array}$ & 13,8 & 12,2 & 15,4 & 0,211 & 5,2 & 13,4 & 14,5 & 13,6 & 0,769 & 14,0 & 11,7 & 12,0 & 11,7 & 0,847 & 5,9 \\
\hline PLG (kg/dia) & 17,3 & 19,8 & 21,1 & 0,110 & 6,14 & 15,1 & 19,3 & 18,0 & 0,580 & 24,6 & 12,6 & 14,0 & 13,6 & 0,750 & 24,1 \\
\hline $\begin{array}{l}\text { Gordura } \\
\text { (g/dia) }\end{array}$ & 696 & 83 & 8 & 0 & 7,5 & 574 & 800 & 6 & 3 & 5 & 465 & 541 & 528 & 37 & 2,8 \\
\hline $\begin{array}{l}\text { Proteína } \\
\text { (g/dia) }\end{array}$ & 603 & 671 & 761 & 0,130 & 7,8 & 630 & 720 & 504 & 0,312 & 20,4 & 438 & 462 & 451 & 0,862 & 11,4 \\
\hline $\begin{array}{l}\text { Lactose } \\
\text { (g/dia) }\end{array}$ & 925 & 987 & 1127 & 0,250 & 10,1 & 865 & 1027 & 779 & 0,525 & 25,7 & 645 & 620 & 625 & 0,821 & 7,8 \\
\hline $\begin{array}{l}\text { xtrato seco } \\
\text { tal (g/dia) }\end{array}$ & 2.415 & 2.702 & 3.002 & 0,162 & 8,3 & 2.243 & 2.761 & 2.164 & 0,375 & 18,2 & 1.680 & 1.753 & 1.734 & 0,899 & 11,3 \\
\hline $\begin{array}{l}\text { Extrato seco } \\
\text { deseng. } \\
\text { (g/dia) }\end{array}$ & 1.718 & 1.864 & 2.117 & 0,199 & 9,2 & 1.669 & 1.691 & 1.428 & 0,303 & 18,1 & 1.214 & 1.212 & 1.205 & 0,994 & 9,0 \\
\hline$a(\%)$ & 5,04 & 5,90 & 5,75 & 7 & 5,5 & 4, & 5,21 & 5 , & 0,4 & 23 & 4,0 & 4, & 4,43 & & 17 \\
\hline te & 4,33 & 4,67 & 4,92 & & 3,6 & 4,4 & 4,78 & 3,61 & 0,220 & 13 & 3,61 & 3,82 & 3,79 & 0,574 & 6,1 \\
\hline Lacto & 6,64 & 6,87 & 7,28 & 0,312 & 5,4 & 6,19 & 6,89 & 5,63 & 0,440 & 15,5 & 5,23 & 5,10 & 5,23 & 0,524 & 2,6 \\
\hline $\begin{array}{l}\text { Extrato seco } \\
\text { total }(\%)\end{array}$ & 17,3 & 18,8 & 19,4 & 0,153 & 4,2 & 15,9 & 18,3 & 15,7 & 0,278 & 9,2 & 14,0 & 14,5 & 14,5 & 0,777 & 7,1 \\
\hline $\begin{array}{l}\text { Extrato seco } \\
\text { deseng. }(\%)\end{array}$ & 12,3 & 12,9 & 13,6 & 0,208 & 4,5 & 11,9 & 13,1 & 10,4 & 0,158 & 8,6 & 9,92 & 9,99 & 10,1 & 0,869 & 3,9 \\
\hline
\end{tabular}

$\mathrm{FM}=$ fubá de milho; $\mathrm{FS}=$ farelo de soja; $\mathrm{CV}=$ coeficiente de variação. ${ }^{1}$ Médias seguidas por letras diferentes, dentro de cada tratamento, diferem pelo teste Tukey $(\mathrm{P}<0,10)$.

O peso corporal e a eficiência alimentar relacionada ao CMS (kg de leite/kg de MS consumida) não foram alterados $(\mathrm{P}>0,10)$ pelos tratamentos (Tab. 7). A eficiência alimentar em relação ao fornecimento de concentrado $(\mathrm{kg}$ de leite/kg de concentrado) não alterou $(\mathrm{P}>0,10)$ ao se trabalhar com diferentes níveis de farelo de soja misturado ao fubá de milho, mantendo-se o nível de concentrado constante. Entretanto, a eficiência decresceu quando se adicionaram níveis crescentes de farelo de soja ou fubá de milho, em que foram verificados melhores resultados com $0,8 \mathrm{~kg} / \mathrm{dia}$ de farelo de soja ou fubá de milho (Tab. 6). 
Tabela 7. Variação de peso, eficiência do uso de concentrado e eficiência alimentar em vacas mestiças alimentadas com diferentes quantidades de fubá e milho $(\mathrm{kg} / \mathrm{dia})$ e farelo de soja $(\mathrm{kg} / \mathrm{dia})$ em dietas à base de silagem de milho

\begin{tabular}{|c|c|c|c|c|c|c|c|c|c|c|c|c|c|c|c|}
\hline Item & Fubá & de mi & ho+far & relo de & soja $^{1}$ & & Fare & o de $\mathrm{s}$ & $0 \mathrm{a}^{1}$ & & & Fubá & de $\mathrm{m}$ & ilho $^{1}$ & \\
\hline FM: & 2,4 & 1,6 & 0,8 & Valor & $\mathrm{CV}$ & - & - & 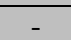 & Valor & $\mathrm{CV}$ & 0,8 & 1,6 & 3,2 & Valor & $\mathrm{CV}$ \\
\hline FS: & 0,8 & 1,6 & 2,4 & $\mathrm{P}$ & $(\%)$ & 0,8 & 1,6 & 3,2 & $\mathrm{P}$ & (\%) & - & - & - & P & $(\%)$ \\
\hline $\begin{array}{l}\text { Peso corporal } \\
(\mathrm{kg})\end{array}$ & 414 & 421 & 434 & 0,42 & 3,81 & 466 & 464 & 496 & 0,37 & 4,89 & 450 & 546 & 419 & 0,12 & 8,38 \\
\hline $\begin{array}{l}\text { Eficiência de uso de } \\
\text { concentrado (kg de } \\
\text { leite/kg de } \\
\text { concentrado) }\end{array}$ & 4,81 & 4,94 & 5,34 & 0,234 & 5,2 & $15,3 \mathrm{a}$ & $9,40 \mathrm{~b}$ & $4,69 b$ & 0,028 & 16,1 & $13,5 \mathrm{a}$ & $7,84 b$ & 4,10 & 0,018 & 13,1 \\
\hline $\begin{array}{l}\text { Eficiência alimentar } \\
\text { (kg leite/kg MS } \\
\text { consumida) }\end{array}$ & 0,95 & 0,99 & 1,06 & 0,403 & 7,2 & 1,08 & 1,05 & 0,92 & 0,524 & 14,4 & 1,04 & 0,93 & 0,82 & 0,110 & 7,3 \\
\hline
\end{tabular}

$\overline{\mathrm{FM}}$ = fubá de milho; $\mathrm{FS}$ = farelo de soja; $\mathrm{CV}=$ coeficiente de variação. ${ }^{\mathrm{I}}$ Médias seguidas por letras diferentes, dentro de cada tratamento, diferem pelo teste Tukey $(\mathrm{P}<0,10)$.

\section{DISCUSSÃO}

$\mathrm{O}$ maior consumo de $\mathrm{PB}$ deve-se à maior disponibilidade desse nutriente na dieta, em virtude da adição de concentrado. Nas dietas à base de farelo de soja e dietas à base de fubá de milho, o aumento do consumo de MS, MO, EE, CNF e NDT, nas dietas contendo maiores níveis de concentrado, deve-se à maior densidade física do concentrado, com diminuição do tamanho de partículas em relação ao volumoso, tendo, como consequência, maior taxa de passagem da digesta pelo trato gastrintestinal, possibilitando o aumento do consumo (Owens e Goetsch, 1993). Resultados semelhantes foram encontrados em estudos com diferentes proporções de concentrado com vacas holandesas confinadas (Costa et al., 2005; Silva et al., 2009).

O aumento do consumo de FDN, observado neste experimento, mostra um efeito associativo positivo entre o aumento de concentrado e a digestão da fibra, havendo elevação do consumo de concentrado concomitantemente ao aumento do consumo de silagem de milho. Resposta quadrática para o consumo de FDN tem sido observada, similarmente ao ocorrido neste experimento, como é o caso dos trabalhos desenvolvidos por Gesualdi et al. (2000) e Silva et al. (2002).

$\mathrm{O}$ maior consumo de $\mathrm{PB}$, no concentrado à base de farelo de soja, provavelmente influenciou a maior digestibilidade da $\mathrm{PB}$ devido à diluição da fração endógena de nitrogênio no total de nitrogênio excretado (Coelho da Silva e Leão, 1979).
A diminuição do coeficiente de digestibilidade da MS, MO, CNF e NDT, encontrada neste trabalho em dietas à base de fubá de milho, contradiz a expectativa de aumento de digestibilidade dessas frações nutricionais. No entanto, a diminuição da digestibilidade desses constituintes deve estar associada ao maior consumo, que pode ter ocasionado maior taxa de passagem e, portanto, reduziu o tempo de permanência dos alimentos no trato gastrintestinal, reduzindo a digestibilidade da dieta, já que a digestão é resultante da interação entre as taxas de degradação e de permanência da digesta nos locais de digestão (Van Soest, 1994).

Esperava-se que o aumento de concentrado na dieta influenciasse positivamente a produção de leite, devido à elevação do fornecimento de energia, com diminuição da proporção de volumoso, fato não ocorrido neste experimento. A justificativa para tais resultados pode estar associada à baixa eficiência alimentar ( $\mathrm{kg}$ de leite produzido/kg de MS consumida), constatada neste experimento, pois, segundo Hutjens (2005), a faixa de eficiência alimentar considerada ideal para aumento da produção de leite deve ficar entre 1,4 e $1,56 \mathrm{~kg}$ de leite/ $\mathrm{kg}$ de $\mathrm{MS}$, enquanto neste experimento a faixa de eficiência ficou entre 0,82 e 1,08 (Tab. 4). Pode-se inferir que os nutrientes adicionados pela dieta, com o aumento do concentrado, não foram suficientes para serem convertidos em produção de leite.

O NRC (National..., 2001) fornece recomendações para suplementação com lisina e metionina, relativas à proteína metabolizável 
total, com base nos trabalhos de Schwab et al. (1992) e Rulquin et al. (1993). Esses autores observaram que a síntese de proteína do leite é maximizada quando os teores de lisina e metionina na proteína metabolizável são de 7,2\% e $2,4 \%$, respectivamente. A relação ótima de Lis:Met é próxima de 3:1, sendo que relações inferiores têm se mostrado pouco eficazes no aumento da proteína do leite de vacas leiteiras. A fonte de proteína usada neste experimento foi o farelo de soja, que, embora seja rico em proteína, não atende às proporções estabelecidas acima para aumento de proteína do leite, haja vista ser deficiente em lisina. Este é, provavelmente, o motivo da não alteração dos teores de proteína do leite ocorrida neste experimento.

Quanto ao teor de gordura do leite, esperava-se que houvesse diminuição, à medida que se aumentou a quantidade de concentrado na dieta, devido, principalmente, à redução do nível de fibra, o que, geralmente, resulta numa série de eventos, que ocorrem em cascata: menor mastigação pelo animal; menor secreção de saliva, com consequente diminuição do tamponamento do rúmen; maior produção de ácidos graxos voláteis; decréscimo do $\mathrm{pH}$ ruminal; mudança da população microbiana ruminal; e redução da relação acetato:propionato (Mertens, 2001). Todos esses fatores contribuem para a diminuição do teor de gordura do leite do animal. Contudo, neste experimento, os teores de gordura do leite permaneceram inalterados. Tal comportamento dos teores de gordura do leite possivelmente é explicado pelo fato de que, mesmo se aumentando a proporção de concentrado, o consumo de volumoso e o consumo de FDN permaneceram constantes ou, até mesmo, aumentaram (Tab. 6), mantendo-se, assim, provavelmente, a produção de acetato, não interferindo nos teores de gordura do leite.

A redução da eficiência alimentar com ao aumento de milho e farelo de soja se dá pelo limite biológico de utilização, conforme Lana (2009), que demonstrou comportamento curvilíneo na resposta animal em função do fornecimento de nível crescente de suplementação.

\section{CONCLUSÕES}

O fornecimento de fubá de milho ou farelo de soja, nas quantidades analisadas neste experimento, para vacas mestiças com 80 dias de lactação, tendo como volumoso a silagem de milho, não promove aumento da produção de leite ou de seus constituintes, sendo que a eficiência do uso do concentrado diminui ao se elevar o nível de suplementação.

\section{REFERÊNCIAS}

CASALI, A.O.; DETMANN, E.; VALADARES FILHO, S.C. et al. Influência do tempo de incubação e do tamanho de partículas sobre os teores de compostos indigestíveis em alimentos e fezes bovinas obtidos por procedimentos in situ. Rev. Bras. Zootec., v.37, p.335-342, 2008.

COELHO DA SILVA, J.F.C.; LEÃO, M.I. Fundamentos de nutrição de ruminantes. Piracicaba: Livro Ceres. 1979. 380p.

COSTA, M.G.; CAMPOS, J.M.S.; VALADARES FILHO, S.C. et al. Desempenho produtivo de vacas leiteiras alimentadas com diferentes proporções de cana-de-açúcar e concentrado ou silagem de milho na dieta. Rev. Soc. Bras. Zootec., v.34, p.2437-2445, 2005.

DETMANN, E.; VALADARES FILHO, S.C. On the estimation of non-fibrous carbohydrates in feeds and diets. Arq. Bras. Med. Vet. Zootec. [online], v.62, p.980-984, 2010. Acessado em: 21 de maio de 2015. Disponível em: http://dx.doi.org/10.1590/S010209352010000400030

GESUALDI JR., A.; PAULINO, M.F.; VALADARES FILHO, S.C. et al. Concentrate levels in the diet for crossbred Limousin $\mathrm{x}$ Nellore bulls: Intake, feed:gain ratio and weight gain. Rev. Bras. Zootec., v.29, p.1458-1466, 2000 .

GRANT, R.J.; ALBRIGHT, J.L. Feeding behavior and management factors during the transition period in dairy cattle. J. Anim. Sci., v.73, p.2791-2803, 1995.

HUTJENS, M.F. Feed efficiency and its economic impact on large herds. In: Proceedings of the 20th Annual Southwest Nutrition \& Management Conference. Tempe, AZ, USA, 2005. p.186-191. 
INTERNATIONAL Dairy Federation-IDF. Whole milk determination of milk fat, protein and lactose content. Guide for the operation of mid infrared instruments. Bruxelas: 1996.12p. (IDF Standart 141 B)

JANSSEN, H.P. Alimentação da vaca recémparida. In: SIMPÓSIO SOBRE PRODUÇÃO DE LEITE, TÉCNICAS E ATERNATIVAS, 1994, Castro. Anais... Castro: Fundação ABC e Cooperativa Central de Laticínios do Paraná, 1994. p.68-74.

LANA, R.P. Sistema Viçosa de formulação de rações. 4.ed. Viçosa: Editora UFV, 2007. 91p.

LANA, R.P. Uso racional de recursos naturais não renováveis: aspectos biológicos, econômicos e ambientais. Rev. Bras. Zootec., v.38, p.330340, 2009. (suplemento Especial).

LICITRA, G.; HERNANDEZ, T.M.; VAN SOEST, P.J. Standarization of procederes for nitrogen fractionation of ruminant feeds. Anim. Feed Sci. Techn., v.57, p.347-358, 1996.

MERTENS, D.R. FDN fisicamente efetivo e seu uso na formulação de ração para vacas leiteiras. In: SIMPÓSIO INTERNACIONAL DE BOVINOCULTURA DE LEITE: NOVOS CONCEITOS EM NUTRIÇÃO. 2., 2001. Lavras, MG: UFLA, 2001. p.38.

MERTENS, D.R. Gravimetric determination of amylase-treated neutral detergent fiber in feeds with refluxing in beaker or crucibles: collaborative study. J. AOAC Internat., v.85, p.1217-1240, 2002.

NATIONAL Research Council-NRC. Nutrient requirements of dairy cattle. 7.ed. Washington, DC: Academic Press, 2001. 381p.

OLIVEIRA, T.S.; LANA, R.P.; GUIMARÃES, G. Crescimento animal e produção de leite em função do suprimento de nutrientes seguem o modelo de saturação cinética de MichaelisMenten. Rev. Bras. Agrop. Sust., v.1, p.91-99, 2011.

OWENS, F.N.; GOETSH, A.L. Fermentação ruminal. In: CHURCH, D.C. El rumiante: fisiologia digestiva y nutricion. Espanha: Acríbia, 1993. p.159-190.
RULQUIN, H.; PISULEWSKI, P.M.; VE'RITE', R. et al. Milk production and composition as a function of postruminal lysine and methionine supply: A nutrient- response approach. Livest. Prod. Sci., v.37, p.69-90, 1993.

SCHWAB, C.; BOZAK, C.K.; WHITEHOUSE, N.L. et al. Amino acid limitation. J. Dairy Sci., v.75, p.3503-3518, 1992.

SILVA, C.V.; LANA, R.P.; CAMPOS, J.M.S. et al. Intake, apparent nutrient digestibility and performance of milking cows under pasture as a function of levels of concentrate and crude protein in the diet. Rev. Bras. Zootec., v.38, p.1372-1380, 2009.

SILVA, D.J.; QUEIROZ, A.C. Análise de alimentos (métodos químicos e biológicos). 3.ed. Viçosa, MG: Universidade Federal de Viçosa, 2002. 235p.

SKLAN, D.; ASHKENAZI, R.; BRAUN, A. et al. Fatty acids, calcium soaps of fatty acid and cottonseeds fed to high yielding cows. J. Dairy Sci., v.75, p.2463-2472, 1992.

SNIFFEN, C.J.; O' CONNOR, J.D.; Van SOEST, P.J. et al. A net carbohydrate and protein system for evaluating cattle diets. II. Carbohydrate and protein availability. J. Anim. Sci., v.70, p.3562-3577, 1992.

STATISTICAL ANALYSIS SYSTEM - SAS. SAS system: SAS/STAT. Version 9.0 (software). Cary: SAS Institute, 2004. (CD-ROM).

VALADARES FILHO, S.C.; BRODERICK, G.A.; VALADARES, R.F.D. et al. Effect of replacing alfalfa silage with high moisture corn on nutrient utilization and milk production. $J$. Dairy Sci., v.83, p.106-114, 2000.

VAN SOEST, P.J. Nutritional ecology of the ruminant. 2. ed. Ithaca, NY: Cornell University Press, 1994. 476p.

WEISS, W.P.; CONRAD, H.R.; St.PIERRE, N.R. A theoretically based model for predicting total digestible nutrient values of forage and concentrates. Anim. Feed Sci. Techn., v.39, n.12, p.95-110, 1992. 